\title{
Knowledge and Practices of Pregnant Women Regarding Danger Signs of Obstetric Complications
}

\author{
Anaam Ebrahim El-Nagar ${ }^{1}$, Manal Hassan Ahmed ${ }^{2}$,Ghada Abd El-Salam Belal ${ }^{3}$ \\ ${ }^{I}$ Domenstrator, Obstetric and Gynecological Nursing Dept, Faculty of Nursing, Tanta University, Tanta, Egypt \\ ${ }^{2}$ Prof \& Chairman of Obstetric and Gynecological Nursing Dept, Faculty of Nursing, Tanta University, Tanta, \\ Egypt \\ ${ }^{3}$ Lecturer of Obstetric and Gynecological Nursing Dept, Faculty of Nursing, Tanta University, Tanta, Egypt
}

\begin{abstract}
Knowledge of the danger signs of obstetric complications is an essential step in recognition of complications and enables women to take appropriate action to access emergency care.

Aim: The present study aimed to assess knowledge and practices of pregnant women regarding danger signs of obstetric complications.

Subjects and Method: An exploratory descriptive study was conducted at 4 antenatal clinics (M.C.H centers) affiliated to the different available geographical health zones in Tanta City including: Tanta rabae at Kohafa, Medical center at Said, Tanta Khames at El agizy, and Medical center at Sager. A total sample of 200 pregnant women selected randomly from the previously mentioned settings fulfilling the inclusive criteria was included in the study (50 from each). A structured interview schedule sheet was used to collect the necessary data. It comprised the following parts:
\end{abstract}

Part I: socio-demographic data such as age, level of education and occupation.

Part II: obstetric characteristics such as gravidity, parity, abortion, antenatal follow-up and presence of any complications in previous pregnancies, deliveries and puerperium.

Part III: questions related to knowledge about danger signs of obstetric complications

Part IV: women's practices toward danger signs of obstetric complications.

The results of this study revealed that the most frequently recognized danger signs that may occur during pregnancy were vaginal bleeding, followed by severe abdominal pain and gush of water from the vagina that were mentioned by more than two third, more than half and nearly half of the women, respectively. While, vaginal bleeding was the most commonly known danger sign mentioned by nearly one third and slightly more than one third of the women during labor and puerperium, respectively. Also, the vast majority of the women consulted a doctor when these danger signs appeared.

Conclusion: Poor level of knowledge was reported regarding danger signs of obstetric complications among pregnant women. According to the actual practices taken by women to overcome their danger signs during current pregnancy, consult doctor was the actual mentioned practice and it was also the anticipated practice during labor/delivery and postpartum period. A significant correlation was found between women's level of education, occupation, previous experience with obstetric complications, time of the initial antenatal visit and their knowledge about obstetric danger signs.

Recommendations: the study recommended developing antenatal classes for all pregnant women about obstetric danger signs and about the proper time to seek medical care. In addition, the mass media should be utilized and community organizations mobilized to disseminate correct and relevant information about danger signs of obstetric complications to women, families and communities.

Keywords: Obstetric danger signs, Knowledge, obstetric complications.

\section{Introduction}

Pregnancy and childbirth are special events in women's life and in the live of their families. This can be a time of great hope and joyful anticipation; it can also be a time of fear, suffering and even death ${ }^{(1)}$. Complications of pregnancy and childbirth are often the leading causes of morbidity and mortality among women in childbearing ages in the developing countries ${ }^{(2,3)}$. At least $40 \%$ of all pregnant women will experience some type of complications during their pregnancies. For about $15 \%$ of them, these complications will be potentially life-threatening, and will require immediate obstetric care ${ }^{(1,4,5)}$. WHO estimated that half a million women die annually from pregnancy-related causes and that $99 \%$ of these deaths occur in developing countries $^{(6,7)}$. In Egypt, the national maternal mortality ratio in 2011 was 57 per 100.000 births. While, during 2007-2009, it was 123.94 per 100.000 births in Tanta University Hospital, Egypt ${ }^{(8,9)}$.

The direct complications that account for more than $70 \%$ of maternal deaths are hemorrhage, infection, unsafe abortion, eclampsia, and obstructed labor. While these are the main causes of maternal death; unavailable, inaccessible, unaffordable, or poor quality care is fundamentally responsible ${ }^{(10,11)}$. 
There are also three levels of delays that contribute to these deaths which are known as barriers in seeking emergency obstetric care when maternal complications occur. These levels are: delay in making decision to seek care, delay in arrival at a health facility, and delay in receiving adequate treatment ${ }^{(12)}$.

Most maternal deaths are avoidable through well-functioning health system that provides accessible and high quality care from household to hospital level during antenatal, natal and postnatal period. These deaths could be also prevented significantly, if women and their families recognize obstetric danger signs and promptly seek health care ${ }^{(13,14,15)}$.

Obstetric danger signs includes: persistent vomiting, severe abdominal pain, vaginal bleeding during pregnancy and delivery, severe vaginal bleeding after delivery, swelling of the face, fingers, or feet, blurring of vision, fits during pregnancy, severe headache, high grade fever, marked change in fetal movements, and high blood pressure. In addition sudden escape of fluid from the vagina, dysuria, oliguria or anuria, prolonged labor, loss of consciousness, and retained placenta ${ }^{(16,17)}$.

The provision of care for women during preconception, pregnancy and childbirth periods is essential to ensure a healthy and successful outcome of pregnancy for the mother and her newborn ${ }^{(18)}$. Preconception care provides important opportunities for women and their health care providers to identify and manage any health problems through disease screening by risk assessment, prevention and health promotion ${ }^{(19,20)}$. Antenatal care also detects and manages high-risk pregnancies early, and represents a window of opportunity for education and communication to pregnant women so that they well make appropriate choices especially when they are in danger ${ }^{(21)}$

Moreover, natal and postnatal cares are very crucial because these periods represent the period of highest risk of death and disability for both the mother and her newborn ${ }^{(22)}$. Information, education and counseling provided during these periods are key in management of complications as it would improve early detection of complications and reduces the delay in deciding to seek obstetric care ${ }^{(21,23)}$.

So, one of the most important responsibilities of the nurse is to increase awareness of the pregnant woman and her family about the potential danger signs during pregnancy, labor and delivery and during the postpartum period $^{(24)}$.

\section{Significance of the study}

This study therefore aims to assess the current status of knowledge and practices of pregnant women toward danger signs of obstetric complications. This information are necessary for service providers and health management teams for improving the quality of antenatal care services provided to women and will aid them to provide realistic measures to help women deal with it.

\section{Aim of the study}

The aim of this study was to assess knowledge and practices of pregnant women regarding danger signs of obstetric complications.

\section{Research Questions:}

1. What is the knowledge of pregnant women about danger signs of obstetric complications?

2. What are the actions to be taken by the pregnant women toward danger signs of obstetric complications?

\section{Research Design:}

\section{Subjects and Methods}

An exploratory descriptive study design was adopted to conduct this study.

Setting:

This study was carried out at 4 antenatal clinics (M.C.H centers which were randomly selected from all M.C.H centers in Tanta city) affiliated to the different available geographical health zones in Tanta. The settings include:

1) Tanta rabae at Kohafa.

2) Medical center at Said

3) Tanta Khames at El agizy.

4) Medical center at Sager.

\section{Subjects:}

- A total sample of 200 pregnant women attending the antenatal clinics was randomly selected from each of the four previously mentioned settings to be included in this study (Fifty from each one).

- The subjects of this study were selected according to the following criteria:

- Pregnant women with gestational age of at least 12 weeks gestation.

- Primigravida and/or multigravida.

- Pregnant women with normal current pregnancy course.

- Aged 18-35 years. 
Tools for data collection:

A specially-designed structured interview schedule sheet was constructed based on the recent review of literatures to collect the required data regarding the study elements. The interview schedule sheet covered the following parts:

Part one: It assessed the socio-demographic characteristics of women such as: age, residence, level of education, and occupation.

Part two: It included questions related to obstetric characteristics of women such as ; gravidity, parity, number of abortions, presence of obstetrical complications in previous pregnancies, deliveries and puerperium , mode and place of last delivery, time, place of antenatal care, and number of antenatal visits.

Part three: This part assessed women's knowledge about danger signs of obstetric complications. It included 14 questions about: danger signs that may occur during pregnancy, labor and postpartum period, obstetric complications that may occur during pregnancy, delivery and puerperium; whether danger signs are different from obstetric complications, and the women's sources of knowledge about danger signs.

\section{The scoring system regarding women's knowledge was as follow:}

- Women who mentioned more than two danger signs of pregnancy, of childbirth and of postpartum period = good knowledge (was given score 2).

- Women who mentioned two danger signs of pregnancy, of childbirth and of postpartum period = fair knowledge (was given score 1).

- Women who mentioned one danger sign during pregnancy, childbirth or postpartum period or not mentioned any danger signs at all and/or don't know = poor knowledge (was given score zero).

The total knowledge score level calculated by $(13$ questions $\times 2=26)$ which categorized was as follows:

1) Good level of knowledge $\geq 75 \%=(>20$ scores $)$.

2) Fair level of knowledge $50 \%-<75 \%=(13-<20$ scores $)$.

3) Poor level of knowledge $<50 \%=(<13$ scores $)$.

Part four:

This part related to women's practices toward danger signs of obstetric complications that may occur during pregnancy, labor and postpartum period. It included questions about: practices performed by pregnant women to overcome danger signs, anticipated practices and/or measures that may be taken by women regarding any aroused danger signs during labor \& delivery and during postpartum period.

\section{Method:}

Official permission to conduct the study was obtained from the responsible authorities through official letters from Faculty of Nursing explaining the purpose of the study to the Ministry of Health administrative authorities in order to obtain their acceptance to collect necessary data from the selected settings. Then, the permission was obtained from the center's administrative authorities. Tools were developed by the researcher after review of the relevant literature in addition to experts' opinion. A pilot study was carried out on $10 \%$ of the sample "20" pregnant women from 4 M.C.H centers to ascertain the clarity and applicability of the tool.

Women's informed consent was obtained to participate in the study after explaining the purpose of the study. Also, confidentiality and privacy were ascertained regarding the data collected. Data collection lasted 5 months started from, September 2012 and ended by January 2013 and were accomplished in the morning from 9:00 a.m. to 1:00 p.m. Three times per week according to the identified days of the week for antenatal care at the four previously mentioned M.C.H centers.

\section{Statistical design:}

Statistical analysis of the data was carried out and the collected data was organized, categorized, computerized, tabulated and analyzed by statistical package for social science (SPSS version 17). 
III. Results

Table (1): Socio-demographic characteristics of the women

\begin{tabular}{|l|l|l|}
\hline Socio-demographic data & \multicolumn{2}{|l|}{ Women $\mathbf{n}=\mathbf{2 0 0}$} \\
\cline { 2 - 3 } & $\mathbf{n}$ & \% \\
\hline Age(years): & & \\
$18-<24$ & 64 & 32.0 \\
$24-<30$ & 97 & 48.5 \\
$30-35$ & 39 & 19.5 \\
\hline Range & $\mathbf{1 8 - 3 0}$ \\
Mean \pm SD & $\mathbf{2 5 . 7 1 \pm 4 . 0 9}$ \\
\hline Residence: & \multicolumn{2}{|}{} \\
Urban & 112 & 56.0 \\
Rural & 88 & 44.0 \\
\hline Educational level: & \multicolumn{2}{|}{} \\
Illiterate & 15 & 7.5 \\
Read and write & 11 & 5.5 \\
Primary/preparatory & 18 & 9.0 \\
Secondary/diplom & 87 & 43.5 \\
University & 69 & 34.5 \\
\hline Occupation: & & \\
Housewife & 153 & 76.5 \\
Working & 47 & 23.5 \\
\hline Total & $\mathbf{2 0 0}$ & $\mathbf{1 0 0}$ \\
\hline
\end{tabular}

Table (1): Illustrates the socio-demographic characteristics of the women. It was observed that slightly less than half of the women (48.5\%) were aged from 24 to less than 30 years old, with mean age of 25.71 \pm 4.09 and more than half of the women $(56 \%)$ were urban and $(44 \%)$ were rural. Regarding the educational level, it was found that about one third $(34.5 \%)$ of the women had university education and $(43.5 \%)$ had secondary/ diplom education. Concerning the occupation, it was showed that slightly more than three quarters of the women $(76.5 \%)$ were housewives, and $(23.5 \%)$ were workers.

Table (2): Obstetrical history of the women

\begin{tabular}{|l|l|l|}
\hline \multirow{2}{*}{ Obstetrical history } & \multicolumn{2}{|c|}{$\begin{array}{c}\text { Women } \\
\text { n= 200 }\end{array}$} \\
\cline { 2 - 3 } Gravidity: & n & \\
1 & 81 & 40.5 \\
$2-3$ & 96 & 48.0 \\
$>3$ & 23 & 11.5 \\
\hline Parity: & & \\
Nullipara & 93 & 46.5 \\
1 & 54 & 27.0 \\
$2-3$ & 51 & 25.5 \\
$>3$ & 2 & 1.0 \\
\hline Type of last delivery(N=107): & 59 & \\
Normal & 48 & 55.1 \\
Cesarean section & & 44.9 \\
\hline Place of previous delivery (N=107): & 12 & 11.2 \\
Home & 48 & 44.8 \\
Governmental hospital & 47 & 43.9 \\
Private hospital/ doctor's clinic & & \\
\hline Number of abortions: & 163 & 81.5 \\
None & 34 & 17.0 \\
1-2 & 3 & 1.5 \\
\hline 2 & & \\
\hline
\end{tabular}

Table (2): Demonstrates the distribution of the women according to their obstetrical history. It was observed that slightly less than half of the women (48.0\%) were pregnant two to three times, while $46.5 \%$ of the women were nullipara. As regard to the type of last delivery, more than half of the women (55.1\%) had normal spontaneous vaginal delivery and the rest of them (44.9\%) delivered by cesarean section. The governmental hospital was the most commonly reported place of previous last delivery mentioned by (44.8\%) of the women. The table also illustrates that more than three quarters of the women $(81.5 \%)$ had no history of abortions, while only $(1.5 \%)$ had a history of abortions more than two times. 
Knowledge and Practices of Pregnant Women Regarding Danger Signs of Obstetric Complications.

Table (3): Distribution of the women according to their attendance of antenatal care

\begin{tabular}{|l|l|l|}
\hline \multirow{2}{*}{ Antenatal care attendance } & \multicolumn{2}{|c|}{$\begin{array}{c}\text { Women } \\
\text { n=200 }\end{array}$} \\
\cline { 2 - 3 } & n & \% \\
\hline Time of the initial visit: & & \\
First trimester & 157 & 78.5 \\
Second trimester & 37 & 18.5 \\
Third trimester & 6 & 3.0 \\
\hline Place of antenatal care:** & & \\
Governmental hospital & 8 & 4.0 \\
Private hospital/private doctor's clinic & 144 & 72.0 \\
Health centers/MCH & 164 & 82.0 \\
\hline Number of antenatal visits: & & \\
Once & 7 & 3.5 \\
Twice & 17 & 8.5 \\
Three times & 31 & 15.5 \\
Four times & 33 & 16.5 \\
More than four & 112 & 56.0 \\
\hline
\end{tabular}

** More than one answer

Table (3): Illustrates distribution of the women according to their attendance of antenatal care. It was observed that more than three quarters of the women $(78.5 \%)$ sought initial antenatal visit at first trimester and only $(3.0 \%)$ had their initial visit at third trimester. The table also showed that $82.0 \%$ of the women received antenatal care at Health centers, and Maternal and Child Health centers, while $(72.0 \%)$ of the women received antenatal care at private hospital and doctor's clinic and only (4.0\%) of the women received antenatal care at governmental hospital. The table also illustrated that more than half of the women $(56.0 \%)$ had more than four antenatal visits during their current pregnancy, followed by $(15.5 \%$, and $16.5 \%$ respectively) of the women had from 3-4 antenatal visits.

Table (4): Distribution of the women according to presence of maternal and fetal complications

\begin{tabular}{|c|c|c|c|c|}
\hline \multirow[t]{2}{*}{ Maternal and fetal complications } & \multicolumn{2}{|c|}{ Women $\mathrm{n}=\mathbf{2 0 0}$} & \multirow[b]{2}{*}{$\mathbf{X}^{2}$} & \multirow[b]{2}{*}{$\mathbf{P}$} \\
\hline & n & $\%$ & & \\
\hline $\begin{array}{l}\text { Presence of complications in previous pregnancies: } \\
\text { Yes } \\
\text { No }\end{array}$ & $\begin{array}{l}38 \\
162\end{array}$ & $\begin{array}{l}19.0 \\
81.0\end{array}$ & 76.88 & 0.001* \\
\hline $\begin{array}{l}\text { Maternal complications } * * \\
\text { Miscarriage } \\
\text { Placenta praevia } \\
\text { Abruptio placenta } \\
\text { Preterm labor } \\
\text { Pre-eclampsia } \\
\text { Anemia } \\
\text { Hydramnios } \\
\text { RH incompatibility }\end{array}$ & $\begin{array}{l}37 \\
3 \\
1 \\
5 \\
6 \\
7 \\
2 \\
2\end{array}$ & $\begin{array}{l}97.4 \\
7.9 \\
2.6 \\
13.2 \\
15.8 \\
18.4 \\
5.3 \\
5.3\end{array}$ & 60.18 & $0.022 *$ \\
\hline $\begin{array}{l}\text { Fetal complications** } \\
\text { IUFD } \\
\text { Congenital malformations } \\
\text { Abortion }\end{array}$ & $\begin{array}{l}1 \\
1 \\
10\end{array}$ & $\begin{array}{l}2.6 \\
2.6 \\
26.3 \\
\end{array}$ & 16.94 & $0.007 *$ \\
\hline $\begin{array}{l}\text { Presence of complications in previous deliveries: } \\
\text { Yes } \\
\text { No }\end{array}$ & $\begin{array}{l}6 \\
194 \\
\end{array}$ & $\begin{array}{l}3.0 \\
97.0\end{array}$ & 176.72 & $0.001 *$ \\
\hline $\begin{array}{l}\text { Maternal complications } * * \\
\text { Bleeding }\end{array}$ & 4 & 66.7 & 184.24 & $0.001 *$ \\
\hline $\begin{array}{l}\text { Fetal complications** } \\
\text { Prolapsed umbilical cord } \\
\text { Fetal distress } \\
\text { Stillbirth }\end{array}$ & $\begin{array}{l}1 \\
1 \\
2\end{array}$ & $\begin{array}{l}16.7 \\
16.7 \\
33.3\end{array}$ & 0.500 & 0.778 \\
\hline $\begin{array}{l}\text { Presence of complications in previous puerperium: } \\
\text { Yes } \\
\text { No }\end{array}$ & $\begin{array}{l}13 \\
187\end{array}$ & $\begin{array}{l}6.5 \\
93.5\end{array}$ & 151.2 & 0.001* \\
\hline $\begin{array}{l}\text { Maternal complications } * * \\
\text { Postpartum hemorrhage } \\
\text { Puerperal infection } \\
\text { Anemia }\end{array}$ & $\begin{array}{l}4 \\
5 \\
4\end{array}$ & $\begin{array}{l}30.8 \\
38.5 \\
30.8 \\
\end{array}$ & 3.18 & 0.364 \\
\hline $\begin{array}{l}\text { Fetal complications** } \\
\text { Still birth } \\
\text { Meconium aspiration syndrome } \\
\text { Respiratory distress syndrome } \\
\text { Perinatal asphyxia } \\
\text { SGA } \\
\text { Neonatal infection }\end{array}$ & $\begin{array}{l}1 \\
3 \\
2 \\
1 \\
2 \\
1\end{array}$ & $\begin{array}{l}7.7 \\
23.1 \\
15.4 \\
7.7 \\
15.4 \\
7.7\end{array}$ & 3.545 & 0.737 \\
\hline
\end{tabular}


Knowledge and Practices of Pregnant Women Regarding Danger Signs of Obstetric Complications.

Table (4): Shows distribution of the women according to presence of maternal and fetal complications. It was observed that more than three quarters and the majority $(81.0 \%, 97 \%$ and $93.5 \%)$ of the women had no complications in previous pregnancies, deliveries and puerperium, respectively and the rest of them (19\%, 3\%, $6.5 \%$ ) had complications. As regard to maternal complications, miscarriage was the most frequent complication occurred in previous pregnancies mentioned by the majority of the women $(97.4 \%)$, while bleeding was the only reported complication present in previous deliveries mentioned by two third $(66.7 \%)$ and more than one third of the women $(38.5 \%)$ had puerperal infection, followed by postpartum hemorrhage (30.8\%) in previous puerperium.

Table (5): Distribution of the women according to their knowledge regarding obstetrical complications

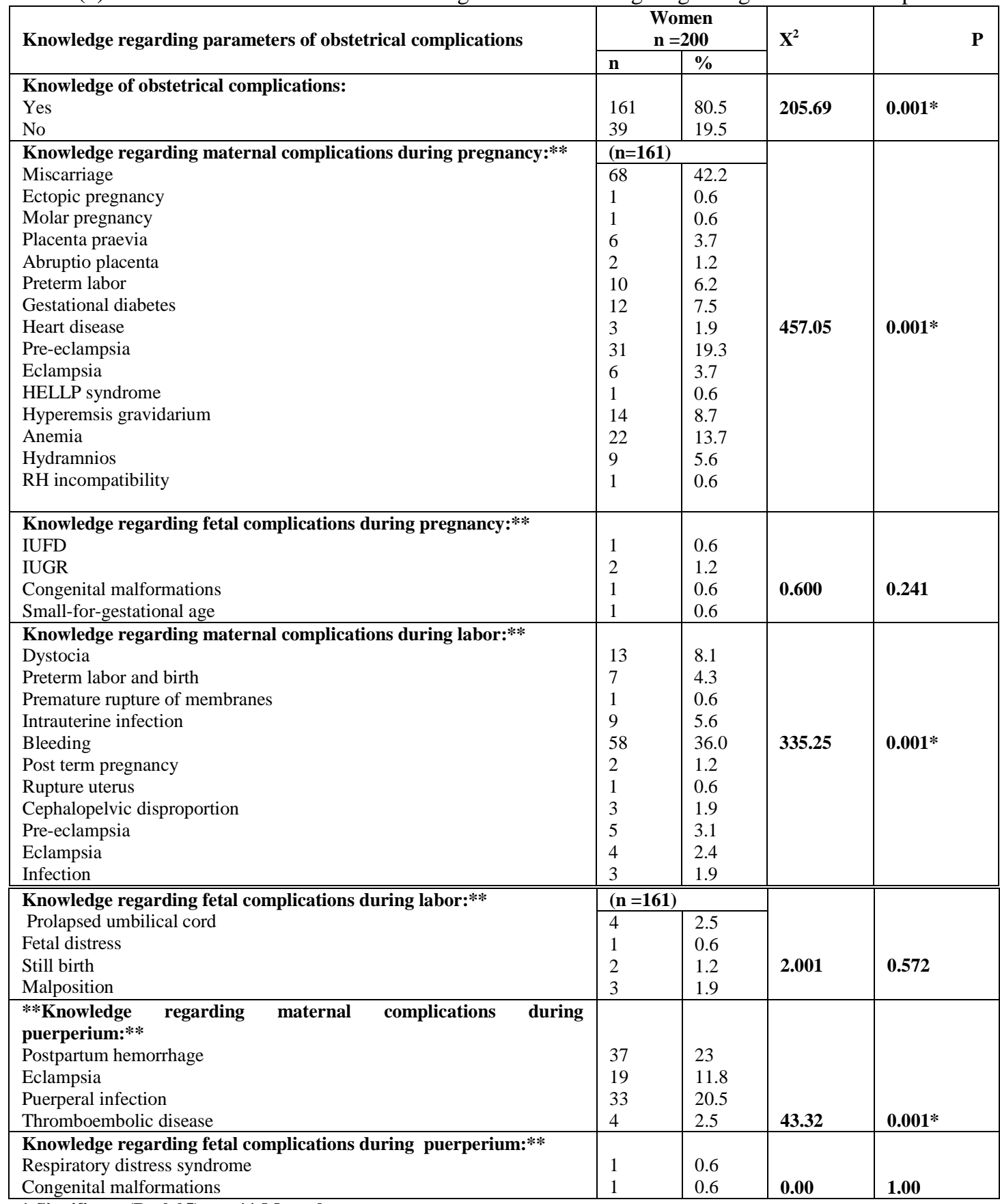

* Significant $(\mathbf{P}<\mathbf{0 . 0 5}) \quad$ *** More than one answer

Table (5): Illustrates the distribution of the women according to their knowledge regarding obstetrical complications. It was found that more than three quarters of the women (80.5\%) had knowledge of obstetrical complications that may occur during pregnancy, labor, and puerperium, while only (19.5\%) had no knowledge. 
Regarding the knowledge of maternal complications during pregnancy, labor, and puerperium, it was observed that miscarriage, bleeding, and postpartum hemorrhage were the most commonly known complications by $(42.2 \%, 36 \%$, and $23 \%)$ of the women, respectively.

Table (6): Distribution of the women according to their knowledge regarding danger signs of obstetric complications

\begin{tabular}{|c|c|c|c|c|}
\hline \multirow[t]{2}{*}{ Knowledge regarding danger signs of obstetric complications } & \multicolumn{2}{|c|}{$\begin{array}{l}\text { Women } \\
\mathrm{n}=\mathbf{2 0 0}\end{array}$} & \multirow[t]{2}{*}{$\mathbf{X}^{2}$} & \multirow[t]{2}{*}{$\mathbf{P}$} \\
\hline & $\mathbf{n}$ & $\%$ & & \\
\hline $\begin{array}{l}\text { Knowledge regarding danger signs of obstetric complications: } \\
\text { Yes } \\
\text { No }\end{array}$ & $\begin{array}{l}149 \\
51\end{array}$ & $\begin{array}{l}74.5 \\
25.5\end{array}$ & 55.12 & $0.001 *$ \\
\hline $\begin{array}{l}\text { Are danger signs that may occur during pregnancy, labor or } \\
\text { puerperium are different from obstetric complications? } \\
\text { Yes } \\
\text { No }\end{array}$ & $\begin{array}{l}123 \\
77\end{array}$ & $\begin{array}{l}61.5 \\
38.5\end{array}$ & 10.58 & $0.001 *$ \\
\hline $\begin{array}{l}\text { Are the danger signs predisposing to obstetric complications? } \\
\text { Yes } \\
\text { No }\end{array}$ & $\begin{array}{l}133 \\
67 \\
\end{array}$ & $\begin{array}{l}66.5 \\
33.5 \\
\end{array}$ & 21.78 & $0.001 *$ \\
\hline $\begin{array}{l}\text { What are danger signs during pregnancy?** } \\
\text { Vaginal bleeding } \\
\text { Swelling of the face and fingers } \\
\text { Continuous severe headache } \\
\text { Vision changes } \\
\text { Decreased urine output } \\
\text { High blood pressure } \\
\text { Convulsion } \\
\text { Severe backache } \\
\text { Severe abdominal pain } \\
\text { High grade fever } \\
\text { Severe vomiting } \\
\text { Gush of water from the vagina } \\
\text { Abnormal fetal movements } \\
\text { Burning sensation with urination } \\
\text { Regular uterine contraction }\end{array}$ & $\begin{array}{l}103 \\
14 \\
31 \\
14 \\
5 \\
26 \\
1 \\
66 \\
91 \\
17 \\
8 \\
70 \\
52 \\
11 \\
23 \\
\end{array}$ & $\begin{array}{l}69.1 \\
9.4 \\
20.8 \\
9.4 \\
3.4 \\
17.4 \\
0.7 \\
44.3 \\
61.1 \\
11.4 \\
5.4 \\
47 \\
34.9 \\
7.4 \\
15.4 \\
\end{array}$ & 48.02 & $0.002 *$ \\
\hline $\begin{array}{l}\text { What are danger signs during labor?** } \\
\text { Vaginal bleeding } \\
\text { Prolonged labour } \\
\text { Severe headache } \\
\text { High or low blood pressure } \\
\text { Retained placenta } \\
\text { Inadequate or prolonged contractions } \\
\text { High grade fever } \\
\text { Increasing apprehension } \\
\text { High or low fetal heart rate } \\
\text { Prolapsed umbilical cord }\end{array}$ & $\begin{array}{l}45 \\
1 \\
1 \\
4 \\
1 \\
3 \\
4 \\
2 \\
10 \\
1\end{array}$ & $\begin{array}{l}30.2 \\
0.7 \\
0.7 \\
2.7 \\
0.7 \\
2.0 \\
2.7 \\
1.4 \\
6.7 \\
0.7\end{array}$ & 310.79 & $0.002 *$ \\
\hline What are danger signs during puerperium?** & \multicolumn{2}{|c|}{$(n=149)$} & \multirow[b]{2}{*}{$\mathbf{5 7 . 5 2}$} & \multirow[b]{2}{*}{$0.011 *$} \\
\hline $\begin{array}{l}\text { Vaginal bleeding } \\
\text { Increase pulse rate } \\
\text { High grade fever } \\
\text { Foul-smelling lochia } \\
\text { Severe headache } \\
\text { Uterine atony } \\
\text { High or low blood pressure } \\
\text { Convulsion } \\
\text { Loss of consciousness } \\
\text { Calf pain } \\
\text { Depression }\end{array}$ & $\begin{array}{l}55 \\
1 \\
44 \\
5 \\
2 \\
1 \\
2 \\
1 \\
1 \\
1 \\
1\end{array}$ & $\begin{array}{l}36.9 \\
0.7 \\
29.5 \\
3.4 \\
1.3 \\
0.7 \\
1.3 \\
0.7 \\
0.7 \\
0.7 \\
0.7\end{array}$ & & \\
\hline
\end{tabular}
* Significant $(\mathbf{P}<\mathbf{0 . 0 5})$
** More than one answer

Table (6): Demonstrates the distribution of the women according to their knowledge regarding danger signs of obstetric complications. It showed that more than half of the women $(61.5 \%)$ gave correct answers regarding the concept that danger signs during pregnancy, labor, and puerperium are different from obstetric complications and almost two third $(66.5 \%)$ of the women reported that danger signs are predisposing to obstetric complications. As regard to knowledge of danger signs during pregnancy, it was found that the most frequently recognized danger signs that may occur during pregnancy were vaginal bleeding mentioned by more than two third $(69.1 \%)$ of the women, followed by severe abdominal pain $(61.1 \%)$ and gush of water from the 
vagina $(47 \%)$. While, vaginal bleeding also was the most commonly recognized danger sign during labor that mentioned by $(30.2 \%)$ of the women and during puerperium, the most commonly known danger signs by the women were vaginal bleeding, and high grade fever that were mentioned by $(36.9 \%$ and $29.5 \%)$ of the women, respectively.

Figure (1): Distribution of the studied women according to their overall knowledge total score level regarding danger signs of obstetric complications.

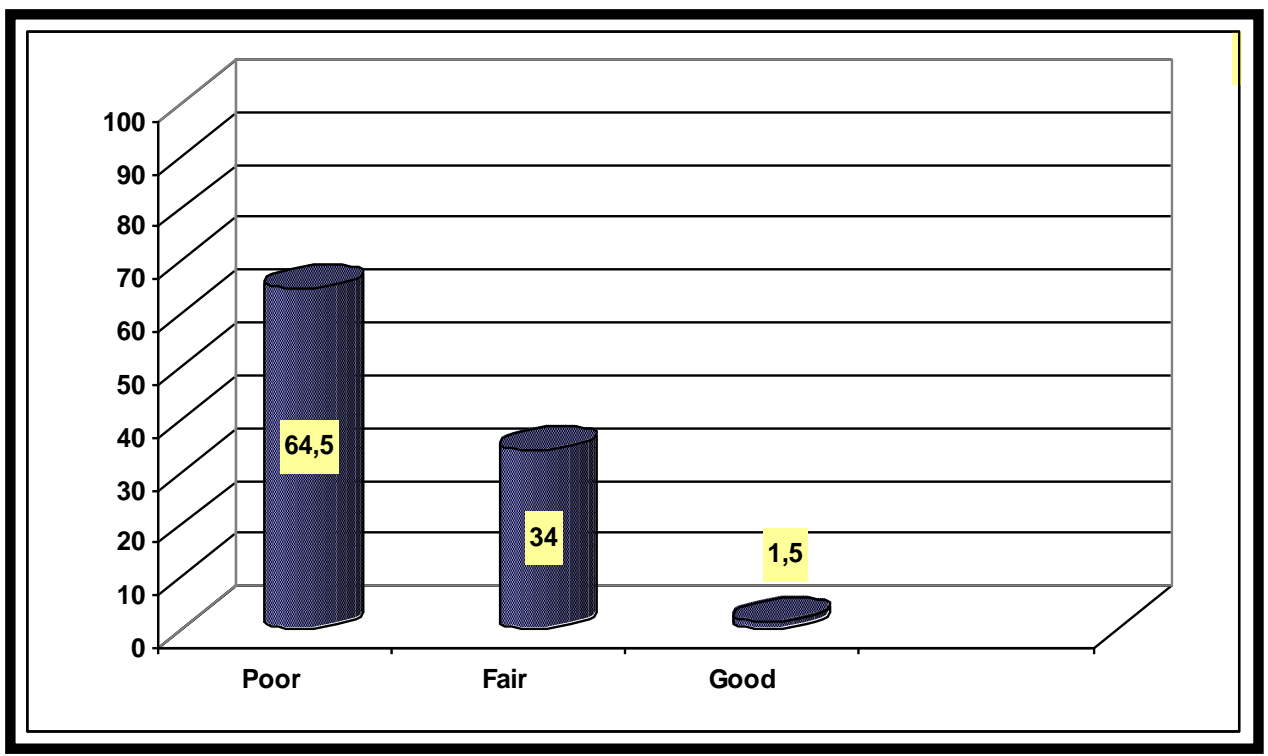

Figure (1): Revealed the distribution of the women according to their overall knowledge total score level regarding danger signs of obstetric complications. It was noticed that about two thirds $(64.5 \%)$ of the women exhibited poor knowledge regarding danger signs of obstetric complications compared to slightly more than one third of the women $(34.0 \%)$ that had fair knowledge, while only $(1.5 \%)$ of the women exhibited good knowledge about such signs.

Table (7): Distribution of the women according to their practices regarding danger signs of obstetric complications

\begin{tabular}{|c|c|c|c|c|}
\hline \multirow[t]{2}{*}{ Practices items } & \multicolumn{2}{|c|}{$\begin{array}{l}\text { Women } \\
\quad \mathbf{n}=\mathbf{2 0 0} \\
\end{array}$} & \multirow[t]{2}{*}{$\mathbf{X}^{2}$} & \multirow[t]{2}{*}{$\mathbf{P}$} \\
\hline & $\mathbf{n}$ & $\%$ & & \\
\hline \multicolumn{5}{|l|}{$\begin{array}{l}\text { Practices to overcome danger signs during current pregnancy } \\
(\mathrm{N}=70): * *\end{array}$} \\
\hline Contact with a doctor & 67 & 95.7 & & \\
\hline Going to hospital & 35 & 50.0 & 35.46 & $0.001 *$ \\
\hline Get more rest & 23 & 32.9 & & \\
\hline \multicolumn{5}{|l|}{$\begin{array}{l}\text { Anticipated practices to overcome any arose danger signs } \\
\text { during labor \& delivery and postpartum period :** }\end{array}$} \\
\hline Consult others (mothers and relatives) & 10 & 7.6 & & \\
\hline Self-care practices (treat myself / self-prescribed medications) & 3 & 2.3 & & \\
\hline Sleep on my back and don't move & 3 & 2.3 & & \\
\hline Go to hospital & 47 & 36.2 & 125.42 & 0.021 \\
\hline Contact with a doctor & 55 & 42.3 & & \\
\hline
\end{tabular}

* Significant $(\mathbf{P}<0.05) \quad * *$ More than one answer

Table (7): Presents the distribution of the women according to their practices regarding danger signs of obstetric complications. Regarding practices performed by the women toward danger signs during current pregnancy, the majority of the women $(95.7 \%)$ contact with a doctor, while anticipated practices to overcome any arosed danger signs during labor \& delivery and postpartum period will consult a doctor and go to hospital mentioned by nearly half and more than one third $(42.3 \%$ and $36.2 \%)$ of the women, respectively. 
Knowledge and Practices of Pregnant Women Regarding Danger Signs of Obstetric Complications.

Table (8): Correlation between knowledge total score level regarding danger signs of obstetric complications of the women and their socio-demographic characteristics.

\begin{tabular}{|c|c|c|c|c|c|c|c|c|}
\hline \multirow{3}{*}{$\begin{array}{l}\text { Sociodemographic } \\
\text { characteristics }\end{array}$} & \multicolumn{6}{|c|}{ Knowledge total score level } & \multirow{3}{*}{$\mathbf{F}$} & \multirow{3}{*}{$\mathbf{P}$} \\
\hline & \multicolumn{2}{|c|}{$\begin{array}{l}\text { Poor } \\
(<\mathbf{5 0})\end{array}$} & \multicolumn{2}{|c|}{$\begin{array}{l}\text { Fair } \\
(50-<75)\end{array}$} & \multicolumn{2}{|c|}{$\begin{array}{l}\text { Good } \\
(>75)\end{array}$} & & \\
\hline & n & $\%$ & n & $\%$ & $\mathbf{n}$ & $\%$ & & \\
\hline \multicolumn{9}{|l|}{ Age } \\
\hline $18-<24$ & 46 & 35.7 & 18 & 26.5 & $\mathbf{0}$ & $\mathbf{0 . 0}$ & \multirow{3}{*}{0.056} & \multirow{3}{*}{0.946} \\
\hline $24-<30$ & 54 & 41.9 & 40 & 58.8 & 3 & 100.0 & & \\
\hline $30-35$ & 29 & 22.4 & $\mathbf{1 0}$ & 14.7 & $\mathbf{0}$ & 0.0 & & \\
\hline \multicolumn{9}{|l|}{ Level of education } \\
\hline Illiterate & 13 & 10.1 & 2 & 2.9 & $\mathbf{0}$ & $\mathbf{0 . 0}$ & \multirow{5}{*}{5.105} & \multirow{5}{*}{$0.001 *$} \\
\hline Read and write & 7 & 5.4 & 4 & 5.9 & $\mathbf{0}$ & $\mathbf{0 . 0}$ & & \\
\hline Primary/preparatory & 14 & 10.9 & 4 & 5.9 & $\mathbf{0}$ & $\mathbf{0 . 0}$ & & \\
\hline secondary/diplom & 61 & 47.2 & 26 & 38.2 & $\mathbf{0}$ & 0.0 & & \\
\hline University & 34 & 26.4 & 32 & 47.1 & 3 & 100.0 & & \\
\hline \multicolumn{9}{|l|}{ Occupation } \\
\hline Housewife & 102 & 79.1 & 51 & 75.0 & $\mathbf{0}$ & 0.0 & \multirow[t]{2}{*}{5.362} & \multirow[t]{2}{*}{ 0.005* } \\
\hline Working & 27 & 20.9 & 17 & 25.0 & 3 & 100.0 & & \\
\hline \multicolumn{9}{|l|}{ Residence } \\
\hline Urban & 68 & 52.7 & 42 & 61.7 & 2 & 66.7 & \multirow[t]{2}{*}{0.805} & \multirow[t]{2}{*}{0.449} \\
\hline Rural & 61 & 47.3 & 26 & 38.2 & 1 & 33.3 & & \\
\hline
\end{tabular}

* Significant $(\mathbf{P}<\mathbf{0 . 0 5})$

Table (8): Reveals the correlation between knowledge total score level regarding danger signs of obstetric complications of the women and their socio-demographic characteristics. The table illustrated that there is a significant relationship between women's level of education, occupation of the women and their knowledge total score level regarding danger signs of obstetric complications, and the difference was statistically significant $(\mathrm{p}=\mathbf{0 . 0 0 1}$ and $\mathbf{0 . 0 0 5})$ respectively.

Table (9): Correlation between knowledge total score level regarding danger signs of obstetric complications of the women and their obstetrical history.

\begin{tabular}{|c|c|c|c|c|c|c|c|c|}
\hline \multirow{3}{*}{ Obstetrical history } & \multicolumn{6}{|c|}{ Total knowledge score } & \multirow{3}{*}{$\mathbf{F}$} & \multirow{3}{*}{$\mathbf{P}$} \\
\hline & \multicolumn{2}{|c|}{$\begin{array}{l}\text { Poor } \\
(<50)\end{array}$} & \multicolumn{2}{|c|}{$\begin{array}{l}\text { Fair } \\
(50-<75)\end{array}$} & \multicolumn{2}{|c|}{$\begin{array}{l}\text { Good } \\
(>75)\end{array}$} & & \\
\hline & $\mathbf{n}$ & $\%$ & n & $\%$ & n & $\%$ & & \\
\hline \multicolumn{9}{|l|}{ Parity } \\
\hline Nullipara & 61 & 47.3 & 29 & 42.6 & 3 & 100.0 & \multirow[t]{4}{*}{1.528} & \multirow[t]{4}{*}{0.220} \\
\hline 1 & 33 & 25.6 & 21 & 30.9 & $\mathbf{0}$ & 0.0 & & \\
\hline $2-3$ & 35 & 27.1 & 16 & 23.5 & $\mathbf{0}$ & 0.0 & & \\
\hline$>3$ & $\mathbf{0}$ & 0.0 & 2 & 2.9 & $\mathbf{0}$ & 0.0 & & \\
\hline \multicolumn{9}{|c|}{ Previous occurrence of maternal and fetal complications $(n=107)$} \\
\hline Yes & 20 & 31.2 & 30 & 75.0 & 1 & 33.3 & \multirow[t]{2}{*}{5.25} & \multirow[t]{2}{*}{ 0.001* } \\
\hline No & 44 & 68.8 & 10 & 25.0 & 2 & 66.7 & & \\
\hline \multicolumn{9}{|c|}{ Time of the initial antenatal visit } \\
\hline First trimester & 92 & 71.3 & 62 & 91.2 & 3 & 100.0 & \multirow[t]{3}{*}{5.501} & \multirow[t]{3}{*}{$0.007 *$} \\
\hline Second trimester & 32 & 24.8 & 5 & 7.3 & $\mathbf{0}$ & 0.0 & & \\
\hline Third trimester & 5 & 3.9 & 1 & 1.5 & $\mathbf{0}$ & $\mathbf{0 . 0}$ & & \\
\hline \multicolumn{9}{|l|}{ Number of antenatal visits } \\
\hline$>4$ visits & 40 & 31.5 & 15 & 22.1 & $\mathbf{0}$ & $\mathbf{0 . 0}$ & \multirow[t]{2}{*}{1.66} & \multirow[t]{2}{*}{0.191} \\
\hline$<4$ visits & 89 & 69.0 & 53 & 77.9 & 3 & 100.0 & & \\
\hline \multicolumn{9}{|l|}{ Place of previous last delivery } \\
\hline Home & 10 & 14.7 & 2 & 5.1 & $\mathbf{0}$ & $\mathbf{0 . 0}$ & \multirow[b]{3}{*}{1.588} & \multirow[b]{3}{*}{0.207} \\
\hline Governmental hospital & 34 & $\mathbf{5 0 . 0}$ & 14 & 35.9 & $\mathbf{0}$ & 0.0 & & \\
\hline $\begin{array}{l}\text { Private hospital/private doctor's } \\
\text { clinic }\end{array}$ & 24 & 35.2 & 23 & 59.0 & 3 & 100.0 & & \\
\hline
\end{tabular}

\section{* Significant $(\mathbf{P}<\mathbf{0 . 0 5})$}

Table (9): Illustrates the correlation between knowledge total score level regarding danger signs of obstetric complications of the women and their obstetrical history. The table revealed that there is a significant relationship between previous occurrence of maternal and fetal complications, and time of the initial antenatal visit and knowledge total score level regarding danger signs of obstetric complications of the women, and the difference was statistically significant $(\mathrm{p}=\mathbf{0 . 0 0 1}$ and $\mathbf{0 . 0 0 7})$ respectively. 
Knowledge and Practices of Pregnant Women Regarding Danger Signs of Obstetric Complications.

\section{Discussion}

Essentially, all women in developing countries are at risk of obstetric complications. These complications are virtually inconceivable to anticipate and hard to forestall .Medical and nursing management for women with obstetric complications begins with the recognition of danger signs. Because lack of knowledge about danger signs of obstetric complications often delays decision-making for health care service seeking, resulting in tragic consequences, where women die at home or in their way to the health facility ${ }^{(25,26)}$.

This study therefore aimed to assess the current status of knowledge and practices of pregnant women toward danger signs of obstetric complications. Concerning the overall knowledge total score level regarding danger signs of obstetric complications, the findings of the present study revealed that about two thirds of the women exhibited poor knowledge regarding danger signs of obstetric complications. These results could be explained according to Egypt Demography and Health Survey (2008) ${ }^{(\mathbf{1 3 , 2 7})}$, who stated that slightly more than one quarter of Egyptian pregnant women didn't receive antenatal care. However, among those who receive antenatal care only one third of them received minimal information about danger signs of obstetric complications and where and when to seek medical assistance.

This finding is in agreement with Pembe et al.(2009) ${ }^{(28)}$, and Hasan \&Nisar (2002) ${ }^{(29)}$. They reported that women generally had poor knowledge of danger signs of obstetric complications. Also, this finding was concur with a study conducted by Hailu et al (2010) ${ }^{(30)}$, and Kabakyenga et al. (2011) ${ }^{(31)}$, who reported low levels of knowledge of obstetric danger signs. While, this finding disagree with Rashad \&Essa(2010) ${ }^{(27)}$. They found that almost only one-quarter of their subjects had poor knowledge of obstetric danger signs which reflect lack of knowledge regarding such signs.

On the other hand, the results of the current study showed that slightly more than one third of the women had fair knowledge regarding danger signs of obstetric complications. This could be explained by the fact that one quarter of the women in the current study were working and one third had university education which may give them opportunity to share knowledge and experience with others. These results go in line with Rashad \&Essa (2010) ${ }^{(27)}$, who reported that nearly one half of their study subjects had fair knowledge of obstetric danger signs.

Unfortunately, the findings of the current study also revealed that only very few women exhibited good knowledge about obstetric danger signs. This corresponds with Rashad \&Essa (2010) ${ }^{(27)}$, who mentioned that only one quarter of their study subjects exhibited good knowledge about obstetric danger signs. Knowledge of obstetric danger signs is important to shape health seeking behaviors which contribute to save women's life that stressed by many authors as Myer \& Harrison (2003) ${ }^{(32)}$, Smith et al. (2004) ${ }^{(33)}$, Stekelenburg et al.(2004) ${ }^{(34)}$, and Sugiarto (2007) ${ }^{(35)}$.

Regarding practices taken by women to overcome danger signs during current pregnancy, the present study indicated that the vast majority of the women stated that they consulted a doctor when danger signs appeared. These findings are different as compared with Sangal et al (2012) ${ }^{(36)}$, who mentioned that more than half of women consulted a health worker/ doctor, and approximately three-quarters of women didn't have any consultation despite knowing their danger signs. Bimala $\mathbf{( 2 0 1 1}^{(\mathbf{3 7})}$, also indicated that most of the respondents had visited health facility when they had danger signs, while slightly more than one tenth either had contact with health personnel or did nothing during such conditions. This discrepancy may be due to difference in perception of the severity of obstetric danger signs among women, knowledge level or difference in cultural background which may affect their practices.

On the other hand, if these danger signs appeared during labor/delivery and postpartum period, the current study revealed that less than half of women mentioned they will consult a doctor. These findings disagree with a result carried out by Mutiso et al. (2008) ${ }^{(\mathbf{3 8})}$, who noticed that the majority of their respondents would seek urgent medical consultation in case of an emergency as opposed to one tenth who would either pray or didn't know what to do.

As regard correlation between knowledge total score level of the women regarding danger signs of obstetric complications and their sociodemographic characteristics, the current study reported that a statistical significant correlation was present between women's level of education, occupation and between knowledge about obstetric danger signs. These results are in agreement with Rashad \&Essa (2010) ${ }^{(27)}$ and Raoof AlHadithi (2011) ${ }^{(39)}$. The similarity between the previous studies and the result of the present study could be justified by the fact that Literate women were more likely to gain knowledge about danger sign from printed media in comparison to illiterate women. In other words, the risk of adverse prenatal outcome goes down as the length of education increases, due to women's ability to follow instructions, start prenatal care early, and attend more visits. Also, working women have better opportunity to share experiences with others than housewives.

Regarding correlation between knowledge total score level of the women knowledge regarding danger signs of obstetric complications and their obstetrical history, the present study reported that the previous occurrence of maternal and fetal complications and time of the initial antenatal visit were significantly associated with knowledge of women about obstetric danger signs. These results are similar with Rashad \& 
Knowledge and Practices of Pregnant Women Regarding Danger Signs of Obstetric Complications.

Essa (2010) ${ }^{(27)}$ and Pembe et al.(2009) ${ }^{(28)}$.The similarity between the previous studies findings and the findings of the present study could be justified by the fact that women with previous complications had their own experience which is an important source of information. Whereas; early initiation of antenatal care provides women with an excellent opportunity for information and early detection of any complications or risk factors.

Accordingly, empowering women with information enables them to understand and articulate their health needs and to seek assistance without delay. Failure to give information keeps women "in the dark" and creates a barrier between the consumers and service providers. Therefore, women's empowerment is a key strategy for maternal mortality reduction through danger sign education and early intervention because it provides them with the capacity to make critical decisions about their own health. It also enables them to seek care when they think they need it, follow medical procedures, and participate in health activities and education

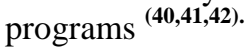

\section{Conclusion}

Poor level of knowledge was reported regarding danger signs of obstetric complications among pregnant women. According to the actual practices taken by women to overcome their danger signs during current pregnancy, consult doctor was the actual mentioned practice by women during current pregnancy and it was also the anticipated practice during labor/delivery and postpartum period. A significant correlation was found between women's level of education, occupation, previous experience with obstetric complications, time of the initial antenatal visit and their knowledge about obstetric danger signs.

\section{Recommendations}

The study recommended developing antenatal classes for all pregnant women about obstetric danger signs and the proper time to seek medical care. In addition, the mass media should be utilized and community organizations mobilized to disseminate correct and relevant information about danger signs of obstetric complications to women, families and communities. Further studies are needed in this field to assess the effect of health education program on women's knowledge and practices regarding obstetric danger signs during pregnancy, labor and postpartum period.

\section{References}

[1]. Radhika K .A study to assess the knowledge of selected warning signs in pregnancy among primi-gravida women in Kempa Cheluvamba general hospital, Master thesis, Bangalore, Rajiv Gandhi University of Health Sciences, Sarvodaya College of Nursing,2005.

[2]. International Institute for Population Sciences, A qualitative assessment of emergency obstetric care in three districts of Maharashtra: A border district cluster strategy for women's right to life and health (summary report), Mumbai, 2004.

[3]. United Nations Population Fund, The promise of equality: Gender equity, reproductive health and the millennium development goals, New York, 2005.

[4]. Gupta N. Maternal mortality: Magnitude causes and concerns, Journal of Obstetrics and Gynaecology Today, 2004; 9(9):555-58.

[5]. Boro E. A study to assess the effectiveness of self instructional module on self-care strategies of antenatal mothers attending outpatient department in selected hospital, Master thesis, Bangalore, Rajiv Gandhi University of Health Sciences, Goutham College of Nursing ,2007.

[6]. Kayode T, Titilayo C, Olapeju A, et al . New paradigm old thinking: The case for emergency obstetric care in the prevention of maternal mortality in Nigeria, BioMed Central Women's Health, 2010; 10(6): 2-8.

[7]. Agus Y, and Horiuchi Sh. Factors influencing the use of antenatal care in Rural West Sumatra, Indonesia, BioMed Central Pregnancy and Childbirth,2012;12(9):1-8.

[8]. Salah El-din A. The last moments in the delivery room, Shorouk Journal, 2013; 1565.

[9]. El-Gharib M, Rakha S, Awara A, et al. Causes of maternal deaths in Tanta University Hospital,Clinical Medicine Reviews in Women's Health Journal, 2010;2:79-83.

[10]. Kavitha P, Prasath R, and Krishnaraj P. A study to assess the effectiveness of structured teaching program on warning signs during pregnancy in terms of knowledge, practice, and attitude among antenatal mothers, Journal of Science, 2012; 2(1):1-5.

[11]. World Health Organization, EMRO country profile, retrieved from http://www.emro.who.int/emrinfo/index.asp?Ctry=egy, available at 5/8/ 2010 .

[12]. Doctor H, Findley S, Cometto G, et al. Awareness of critical danger signs of pregnancy and delivery, preparations for delivery and utilization of skilled birth attendants in Nigeria, Journal of Health Care for the Poor and Underserved, 2013; 24(1):152-70.

[13]. El-Zanaty F, and Way A. Egypt Demography and Health Survey, Egypt, 2008.

[14]. Tamrakar A. A study to evaluate the effectiveness of planned teaching program on knowledge of primigravida regarding selected aspects of safe motherhood in selected hospitals, Master thesis, Bangalore, Rajiv Gandhi University of Health Sciences, Pavan College of Nursing, 2007.

[15]. Johns Hopkins Program for International Education in Gynaecology and Obstetrics (JHPIEGO).Birth preparedness and complication readiness: A matrix of shared responsibilities, USA, 2004.

[16]. Ahmed A, Chaudhry A, Hussain S, et al. Ramification of complications occurring during pregnancy, Science International (Lahore) Journal,2013; 25(1):119-22.

[17]. Johns Hopkins Program for International Education in Gynaecology and Obstetrics (JHPIEGO). Monitoring birth preparedness and complication readiness: Tools and indicators for maternal and newborn health, Baltimore, 2004.

[18]. Tuladhar H, Khanal R, Kayastha S, et al. Complications of home delivery: Our experience of Nepal Medical College Teaching Hospital, Nepal Medical College Journal,2009;11(3): 164- 69.

[19]. American College of Obstetricians and Gynecologists (ACOG), The importance of preconception care in the continuum of women's health care, Obstetrics and Gynaecology,2005;106(3):665-66. 
[20]. Atrash H, Johnson K, Adams M, et al. Preconception care for improving perinatal outcomes: The time to act, Maternal and Child Health Journal, 2006;10(5): 3-11.

[21]. Brugada A. Delivery of prenatal health education and pregnancy outcomes in selected Aeta Tribes in Bataan, International Journal of Public Health Research, 2011;17(49): 11-19.

[22]. Pearson L, Larsson M, Fauveau V, et al. Childbirth care, retrieved from www.who.int/pmnch/media/publications/ aonsection III-3.pdf, available at 17/8/2013.

[23]. Bisika T. The effectiveness of the TBA programme in reducing maternal mortality and morbidity in Malawi, East African Journal of Public Health, 2008 ;5(2):103-10.

[24]. John D, and Catherine T. Guidelines for pregnancy care and management of common obstetric complications by medical officers, retrieved from jknrhm.com/Guideline/Normal delivery and management of obstetric, available at 24 /6/2005.

[25]. Jammeh A, Sundby J, and Vangen S. Barriers to emergency obstetric care services in perinatal deaths in Rural Gambia: A qualitative in-depth interview study, International Scholarly Research Notices Obstetrics and Gynaecology, 2011;10(5): 1-10.

[26]. Khanum P, Quaiyum M, Islam A, et al. Complications of pregnancy and childbirth: Knowledge and practices of women in Rural Bangladesh, retrieved from www.icddrb.org/.../ 1073complications-of-pregnancy-and-childbirthknowledge and practices-ofwomen-in-rural-bangladesh, availableat22/1/ 2000.

[27]. Rashad W, and Essa R. Women's awareness of danger signs of obstetrics complications, Journal of American Science,2010; 6(11): 802-9.

[28]. Pembe A, Urassa D, Carlstedt A, et al . Rural Tanzanian women's awareness of danger signs of obstetric complications, BioMed Central Pregnancy and Childbirth, 2009;9(12): 1-8.

[29]. Hasan I, and Nisar N. Women's perceptions regarding obstetric complications and care in a poor fishing community in Karachi, Journal of Pakistan Medical Association,2002; 52(4):148-52.

[30]. Hailu M, Gebremariam A, and Alemseged F. Knowledge about obstetric danger signs among pregnant women in Aleta Wondo district, Sidama Zone, Southern Ethiopia, Ethiopian Journal of Health Science,2010; 20(1):25-32.

[31]. Kabakyenga J, Ostergren P, Turyakira E, et al. Knowledge of obstetric danger signs and birth preparedness practices among women in rural Uganda, Reproductive Health, 2011; 8(33): 1-10.

[32]. Myer L, and Harrison A. Why do women seek antenatal care late? Perspectives from rural South Africa, Journal of Midwifery and Women's Health, 2003; 48(4): 268-72.

[33]. Smith K, Dmytraczenko T, Mensah B, et al. Knowledge, attitude and practices related to maternal health in Bla, Mali: Result of a baseline survey, Maryland, 2004.

[34]. Stekelenburg J, Kyanamina S, Mukelabai M, et al. Waiting too long: Low use of maternal health services in Kalabo, Zambia, Tropical Medical and International Health, 2004;9(3): 390-98.

[35]. Sugiarto T. Knowledge and practice of maternal health care in Indonesia, Journal of Kependudukan Indonesia, 2007; 2(2):1-16.

[36]. Sangal R, Srivastava R, Singh A, et al. Knowledge and practices regarding obstetric danger signs in women attending ante-natal care clinic at Baba Raghav Das Medical College, Gorakhpur, Indian Journal of Preventive and Social Medicine, 2012;43(1):11-18.

[37]. Bimala B. An exploratory study of prevailing, knowledge, attitude and practice of husband in regards to factors affecting in supporting activities during pregnancy, delivery and post-partum periods, Journal Of Nobel Medical College,2011; 1(1):45-52.

[38]. Mutiso S, Qureshi Z, and Kinuthia J. Birth preparedness among antenatal clients, East African Medical Journal, 2008; 85(6): 275-83.

[39]. Raoof A, and Al-Hadithi T. Antenatal care in Erbil City-Iraq: Assessment of information, education and communication strategy, Duhok Medical Journal, 2011;5(1): 31-40.

[40]. Kuo Ch. A study on community awareness of maternal and perinatal danger signs in Rural Haiti, Master Thesis, North America, University of Connecticut Health Center, 2006.

[41]. Hashem Sh. A study to assess the quality of immediate postpartum nursing care provided to women after cesarean section in Tanta City, Master thesis, Tanta, Tanta University, Faculty of Nursing, 2012

[42]. Kebalepile T. An evaluation of the quality of care midwives provided during the postpartum period in Northern Botswana, Master thesis, Southern Africa, Oslo University, Faculty of Medicine, 2001. 